\title{
Kick-Starting a Strategy for Scooters
}

\author{
Gerald David Flint \\ Utah Valley State College \\ Harold L. Koch \\ The David Eccles School of Business - The University of Utah
}

\begin{abstract}
This is a field-based disguised case that describes a family business decision to enter a market and the consequences of that decision. The primary issue presented in the case is: "What should the family do now?" This issue is one that is not unfamiliar to many small business managers and owners. The case has a difficulty level appropriate for a senior level course in small business management, entrepreneurship, strategic management, marketing, or strategic marketing and can be used to stimulate discussion in MBA classes as well.

\section{Authors' Note}

The authors developed this case study for class discussion rather than to illustrate either effective or ineffective management. This is an actual situation and the facts and details have not been changed in regard to substance or meaning. However, names of individuals, the company, and products bought-sold have been changed for confidentiality.
\end{abstract}

\section{A Different Scooter Market in 2004}

"Hindsight is always 20/20," thought John Patrick (JP) Cody who sure saw things more clearly in 2004 than he did in 2000. Along with his very computer-literate 11-year-old nephew Aaron, JP had just searched "kick scooters" in Google and found a ton of scooters that, four years ago, were just not available; they saw a wide range of prices and market segments - there was the Razor Original Scooter retailing at \$42.99; the Know-Ped for \$115; the Xooter at \$199; the Quadcarver for \$299; the Razor Trikke (3 wheels) retailing for \$200; nine models at Wal-Mart between \$24.97 and \$98.84 even with a

Fisher-Price All-Terrain Switchboard modification, and many more. In addition there were the electric and gasoline scooter models that would carry up to two people.

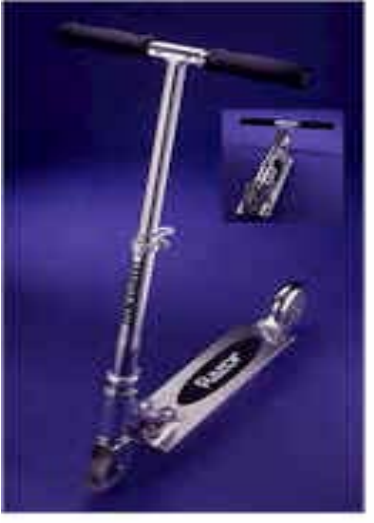

The Razor Rollerboard Scooter (2004), $\$ 40$ (http://extremetoys.com)

"Incredible..." JP mumbled. "This is a great example of shortening Product Life Cycles and Differentiation in the global market, but that was a lesson in markets and competition that was way too expensive. Given everything that happened to us, I still 
wonder what we could have done differently to have avoided the scooter disaster. Should we, could we have done anything differently?"

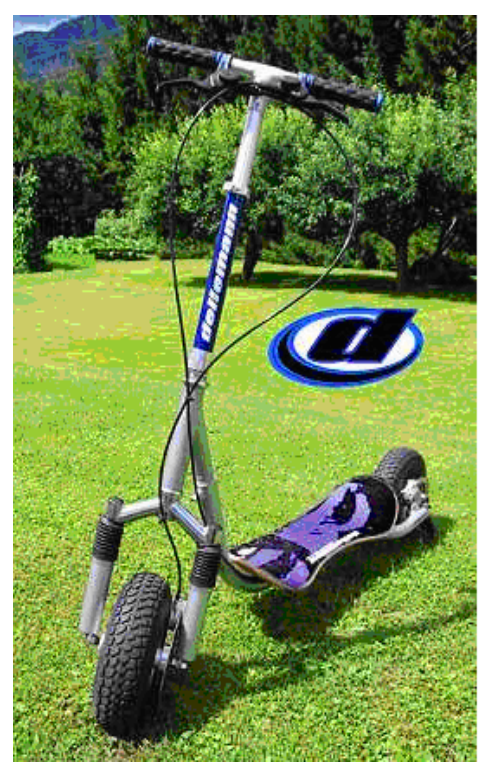

The Dellemann

Mountainscootboard (2004), \$424 (www.scootboard.net)

\section{Short on Strategy and Long on Scooters in 2000}

JP clearly remembered the day back in July of 2001 when he was standing at the entry of the forty-foot shipping container looking at the stacks of cardboard cartons and feeling utterly defeated. Three thousand four hundred SMOOTHX kick scooters remained from the original four thousand that had been packed into the container in spite of his best efforts to move them into retail outlets for Christmas 2000 and spring 2001 !

JP had leaned against the wall of the container and done a quick mental review of the twelve months prior to July 2001. The decisions made and the actions taken had seemed reasonable at first, but the outcomes of those decisions and actions had been very different from what had been expected. He remembered that one of his professors in college had insisted every student learn a very simple rule: "The world is dynamic; things change." Maybe the past few months would help JP never to forget that rule.

\section{We All Thought It Was a Good Idea}

It was in July 2000 that his friends in the import-export business told him that what they thought was a rare business opportunity had opened up in the recreational sports equipment market. The first six months of 2000 had seen an incredible demand for the KNIFE kick scooters. The KNIFE kick scooters had originally appeared in the market in the fall of 1999 and were one of the most sought after Christmas presents in December 1999. Kids from the age of three to students in high school had pestered their parents for the scooters. What was amazing was that the demand for the scooters had remained very high during the first six months of 2000. In fact, the scooters were becoming a hot item for adults in addition to children and adolescents. News stories were being composed and run in major media outlets about how people in New York City, Washington D.C. and other urban areas were adopting the kick scooter as a means of moving along the sidewalks and streets almost as quickly as if riding a bicycle. For example, Time magazine ran an article about scooters in June of 2000 and Newsweek followed with its own article in July of 2000 (Orecklin, 2000; McGinn, 2000).

The KNIFE kick scooters were among the first to market and had sparked the intense demand for the product by introducing some clever technical innovations into what was essentially a skateboard with a handle. The construction of the scooters was of high grade, aircraft quality aluminum, and the engineering design allowed the handle of the scooter to be collapsed and then folded against the footboard. Also, an aluminum 


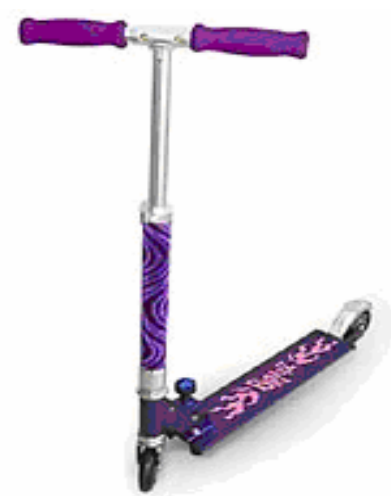

The Bratz Stylin' Scooter by

MGA Entertainment (2004)

\$24.95 (www.walmart.com) braking fixture was an additional feature that gave added control for the rider of the scooter. When collapsed and folded, the kick scooter had dimensions within the range of 4 inches by 3 inches by 24 inches and weighed less than 7 pounds. The lightweight and compact construction of the scooter not only appealed to kids who found them fun and fast, but also to adults who could make an urban journey a little more fun by unfolding a scooter and briefly reverting to a more fun and quick means to go from point $A$ to point $B$ without needing a bike rack or an internal combustion engine.

Until July of 2000, JP had noticed the scooter stories appearing in the news or occasionally had seen the scooters in use on the streets of Capitol City, but he hadn't really thought much about them. Capitol City was a major metropolitan area in the Sun Belt of the country, and scooters were simply something JP noticed as a relatively new addition to the skateboards and bicycles used in the city parks and along the neighborhood streets. His friends changed that lack of attention with one short conversation. Because the demand for the kick scooters and media attention regarding that demand had remained so high in summer of 2000 and because the number and variety of kick scooters in the market was limited, JP's friends had done some investigation regarding the sources for the scooters. They had discovered that the manufacturing company for the KNIFE scooters was based in Taiwan and was interested in introducing another line of scooters into the U.S. market with another model name. Presently, all KNIFE model scooters had to be purchased through the U.S. marketing and distribution company, KNIFE, Inc.

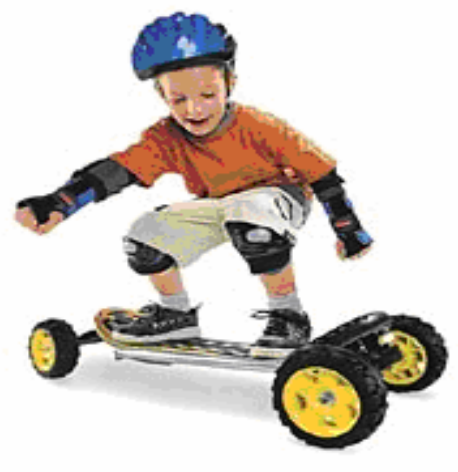

The Fisher-Price All-Terrain Switchboard (2004), \$37.88 (http://www.walmart.com)
The Taiwanese manufacturing company (a partial owner of KNIFE, Inc.) was offering to sell the SMOOTHX model scooter to companies in the U.S. without having to deal with the KNIFE distribution company. The difference between KNIFE and SMOOTHX scooters would be minimal, confined mostly to name, packaging, and the addition of suspension springs to the SMOOTHX model in order to provide a smoother ride experience. The KNIFE scooters ranged in price from $\$ 99$ for the first (and smallest) scooters introduced into the market all the way up to $\$ 149$ for the deluxe models. The suggestion made for the SMOOTHX models was to price them near the low end of the KNIFE models. 


\section{MBA Programs Tell Us First Movers Will Benefit}

JP had immediately been interested in the idea of importing the SMOOTHX scooters when his friends told him about the manufacturing company's idea. They had already contracted with the manufacturing company for a shipment of scooters to be delivered to their region of the U.S. and wondered if JP might be interested in bringing SMOOTHX to the Capitol City area. As JP considered the idea, he decided to involve his family business partners in the discussion. JP was an operational manager of Innovation Enterprises, L.L.C., a limited liability company formed by the siblings of the Cody family to pool their resources for various business endeavors. Several members of the family had bachelor degrees in Business, three were teachers and JP had an MBA from a prestigious western university. There was always somebody that had an informed opinion about the business.

Mostly, Innovation Enterprises dealt with properties (the source of $90 \%$ of revenues) and some retail endeavors related to multi-level marketing of wellness and lifestyle products ( $10 \%$ of revenues), but the family members were always open to new ideas that might bring reasonable returns, and thus, they were interested in the idea of importing the SMOOTHX kick scooters into the Capitol City area. The added flavor of an international aspect made the adventure seem even more interesting.

The strategy of Innovation Enterprises can be summed up by a quote from Dr. Sharon M. Oster, a professor at Yale University: "Our strategy is a commitment to undertake one set of actions rather than another" (Oster, 1990, 4). Arthur Thompson, Jr. and A.J. Strickland III, authors of a strategic management textbook JP had on his shelf, believed that crafting a strategy is an exercise in entrepreneurship since some degree of venturesomeness and risk-taking is inherent in choosing among alternative directions (Thompson \& Strickland, 1999). It seemed that the SMOOTHX was the next step of action for the Cody family. Since it was already a diversified company, a project like the kick scooter seemed just fine and some international work would be a good learning experience.

It was time to run some numbers to determine the feasibility of the project; short-term payback calculations were always run as the first step when new investments were considered by Innovation Enterprises.

\section{The Numbers Look Good}

According to JP's friends, the scooters could be delivered to Capitol City in either the standard twenty-foot shipping containers or forty-foot containers. A twenty-foot container would hold 2000 scooters and a forty-foot container could contain 4000 scooters. The total price for the manufacturing, shipping and ground transport to Capitol City would come to $\$ 51$ per scooter. That meant an initial outlay of $\$ 102,000$ for 2000 scooters or $\$ 204,000$ for 4000 scooters. The family business had ready access to either amount of capital, but the family members were concerned about storage facilities for the scooters and any other overhead costs. 
The family members met to discuss options and plan strategy for the scooters. First, they looked at the costs of importing the scooters. Very quickly, JP had discovered that a friend with a trucking business would allow the container to be delivered to his property, its contents transferred to a standard over-the-road container and then allow that secondary container to be left on the property as long as necessary for $\$ 3$ per day. That storage cost was added to the cost of the scooters and capital as shown below in Exhibit 1.

\section{EXHIBIT 1. Pro Forma Costs of Importing Containers of Scooters}

$\underline{20 \mathrm{ft} \text {. container } \quad 40 \mathrm{ft} \text {. container }}$

Cost of the SMOOTHX scooters:

Cost of storage:

Cost of capital:

90 day turn time on scooters

Total Cost

180 day turn time on scooters

Total Cost
$\$ 102,000$

$\$ 3 /$ day

$10 \%$

$\$ 104,820$

$\$ 107,640$
$\$ 204,000$

$\$ 3 /$ day

$10 \%$

$\$ 209,370$

$\$ 214,740$

Source: Innovation Enterprises, 2000.

The family members did some market testing to determine what demand might exist for the SMOOTHX scooters in the Capitol City area. They learned that bicycle shop owners were having difficulty in procuring KNIFE scooters and were very interested in the SMOOTHX product. Large retailers in the Capitol City area were not approached because it was suspected that they would have their purchasing departments in other cities and would probably want to contract for many more scooters than Innovation Enterprises would care to import. The idea of wholesaling the SMOOTHX scooters in the $\$ 65$ - $\$ 70$ range to bicycle stores that would then sell them in the $\$ 99$ - $\$ 119$ range seemed to find acceptance in the Capitol City area. Also, the large population in the Capitol City area of young families with sizeable disposable incomes indicated that a ready market for the scooters was available. Capitol City had some of the youngest demographic characteristics in the nation with over 30 percent of the population classified by the U.S. Census Bureau as being children. While doing their market research, the family members all agreed that there simply were not many scooters available in the Capitol City market given the market demographics.

What they needed now was an estimate of the proceeds that Innovation Enterprises might realize from selling the scooters and Exhibit 2 below was prepared for presentation to the family. 


\section{EXHIBIT 2. Expected Revenues From Scooter Sales}

\begin{tabular}{|c|c|c|}
\hline & $20 \mathrm{ft}$. container & $40 \mathrm{ft}$. container \\
\hline Promotional marketing & -50 scooters & -50 scooters \\
\hline Gifts to friends and family & -50 scooters & -50 scooters \\
\hline Scooters available to sell & 1900 scooters & 3900 scooters \\
\hline Proceeds at $\$ 65$ / scooter & $\$ 123,500$ & $\$ 253,500$ \\
\hline $\begin{array}{c}\text { Return at } \$ 65 \text { / scooter over } \\
90 \text { days turn time }\end{array}$ & $\$ 18,680(17.8 \%)$ & $\$ 44,130(21.1 \%)$ \\
\hline $\begin{array}{c}\text { Return at } \$ 65 \text { / scooter over } \\
180 \text { days turn time }\end{array}$ & $\$ 15,860(14.7 \%)$ & $\$ 38,760(18.0 \%)$ \\
\hline $\begin{array}{l}\text { Proceeds at } \$ 70 \text { / scooter } \\
\text { Return at } \$ 70 \text { / scooter over }\end{array}$ & $\$ 133,000$ & $\$ 273,000$ \\
\hline $\begin{array}{l}90 \text { days turn time } \\
\text { Return at } \$ 70 \text { / scooter over }\end{array}$ & $\$ 28,180(26.9 \%)$ & $\$ 63,630(30.4 \%)$ \\
\hline 180 days turn time & $\$ 25,360(23.6 \%)$ & $\$ 58,260(27.1 \%)$ \\
\hline
\end{tabular}

Source: Innovation Enterprises, 2000.

\section{Making the Decision}

The time involved for placing an order for scooters and then receiving the scooters was another consideration for the Cody family members. Given that it was July 2000 , the goal would be to receive a shipment as soon as possible, get the scooters into the bicycle shops before Christmas, and then consider the placement of subsequent orders based on how quickly the scooters sold leading up to the Christmas season. Nobody in Innovation Enterprises thought that the demand for scooters would remain high once the 2000 Christmas season passed.

JP's friends estimated that from the time of placing the order, there would be two to three months of time before the scooters would physically be delivered to Capitol City. An order before the end of July or early in August had the probability of arriving in early October, or worst case, in early November. That indicated to JP that they would probably only have one opportunity to bring in scooters for the 2000 Christmas season.

Family members believed that any of the expected returns looked attractive given that their alternative uses of the capital were rather limited at that particular time. The stock market was beginning its long slide downward from the heights of early 2000, and there was no expectation among the members that the downward trend would reverse any time soon. Property investments were also looking less attractive in the summer of 
2000 for Innovation Enterprises, and the retail efforts of the company were small and could not generate the returns expected from the wholesale scooter business.

In thinking about any other costs associated with the scooter business, none of the family members anticipated much opportunity cost in terms of time taken to contact bicycle shop owners and deliver scooters once the shipment was delivered. In fact, they thought of the endeavor as being something fun to do that would earn some money in the process. While none of the members were unconcerned about the size of the investment, none were overly concerned about the impacts upon their other endeavors. Given the lack of scooters in the Capitol City market and the desire of bicycle shop owners to acquire scooters, the members' expectations were that 4000 scooters could be sold during the Christmas 2000 season.

\section{The Order Is Placed}

It was decided to place an order with the Taiwanese manufacturer of the SMOOTHX kick scooters in early August of 2000 and expect delivery sometime in October of 2000. The order was placed through JP's friends, and the entire family followed the order and the process of importation with some interest because they had not engaged in any dealings outside of the U.S. until the time of this venture. The money was wired to JP's friends, who then received a letter of credit from their bank. The Taiwanese manufacturer demanded a letter of credit from JP's friends be in the hands of the company representative before manufacturing would commence. Within a week, the irrevocable and confirmed letter of credit was in place and manufacturing was authorized.

Manufacturing proceeded somewhat faster than anticipated and the container was packed, sealed and ready for shipping from Taiwan before the end of August. JP's friends had arranged with an import / export agent in the Los Angeles area to receive the container and arrange for the overland delivery of the container to Capitol City. The actual ocean transit time for the shipment became somewhat longer than anticipated, but once the container arrived in the port of Los Angeles, was cleared through customs by the import / export agent's staff, and made ready for transport to Capitol City, less than a month had elapsed. Consequently, the agent in Los Angeles contacted JP in the last week of September 2000 and arranged for a delivery time in the Capitol City area for the first week of October.

\section{The Strategy Becomes Complicated}

During August and September 2000 while waiting for the delivery of the order, family members began to notice that several large retail outlets in the Capitol City area began running ads regarding kick scooters. Some of the advertisements were for KNIFE scooters, but there were several other brand names appearing. Also, some of Innovation Enterprises' members began seeing displays of other types of scooters appearing in mall kiosks. By October of 2000 when the SMOOTHX scooters were delivered to Capitol City, several members of the family expressed concern over the 
presence of the new scooter brands in the market. Immediately upon arrival of the container, JP began contacting bicycle shop owners in the Capitol City area to place the scooters.

It was then that the bicycle shop owners informed Innovation Enterprises that a flood of very cheap knockoff scooters had come into the market in the month before the SMOOTHX scooters had arrived. The knockoff scooters were poor imitations of the KNIFE brand line, but they were cheap, and the stores were pulling them in as fast as possible.

Within a month, JP knew that the SMOOTHX scooters were in trouble. While the SMOOTHX quality was superior to all the other brands of scooters in the market except for the KNIFE scooters made by the same manufacturer, there was now little demand for the SMOOTHX because it was not branded as a KNIFE scooter and was more expensive than the cheap imitations in the market. Some of the imitation scooters were being sold wholesale for under $\$ 30$. Retail prices on the KNIFE scooters were not being lowered, but the cheap imitations' prices were falling rapidly. Some of the imitations were selling for under $\$ 50$ at the retail outlets, and some large retailers were providing special promotions with scooters under $\$ 40$.

\section{When It Rains It Pours}

Before the end of November, two other pieces of bad news regarding scooter sales arrived. First, the KNIFE, Inc. organization filed lawsuits against several other scooter manufacturers for patent infringement. Patents in the U.S. protected the KNIFE scooter designs and the distribution company was determined to fight back against the cheap imitation products. While this was actually not of concern in a legal sense to Innovation Enterprises because its scooters were purchased from the manufacturer of the KNIFE scooters, the retailers in Capitol City assumed that the SMOOTHX brand was from a competitor of the KNIFE company and were even more reluctant to carry the alternative line of scooters.

Second, several news media outlets began running stories about scooter-related injuries among children and adults. The news coverage leading into the final weeks of the Christmas 2000 shopping season had numerous stories about broken bones and head injuries sustained by people who had fallen from scooters. While a quick look at the actual statistics would indicate that scooter related injuries were less common than accidents associated with bicycles, automobiles, and skateboards, the news coverage focused upon scooters. Retailers began reporting to Innovation Enterprises that the demand for the scooters was rapidly diminishing.

In an effort to help move sales of the scooters through the bicycle shop outlets, JP decided to try a new strategic tactic. He approached several bicycle shop owners with the idea of taking fairly large consignments of SMOOTHX scooters and participating in some joint advertising through the distribution of flyers in neighborhoods around the various bicycle shops. The storeowners were generally pleased with the idea. The 
family contracted with a local distributor of hand flyers, moved a large number of scooters into seven bicycle shops in the northern section of the Capitol City metropolitan area and flooded that area with roughly 40,000 flyers. The cost for the production and distribution of the flyers was $\$ 4,000$ and Innovation Enterprises would absorb $50 \%$ in the collaborative effort.

\section{Adjustments in the Marketing Mix}

The bicycle stores reported some increase in traffic and sales after the distribution of the advertising flyers, but the response was far less than had been anticipated with only an estimated half-percent response from the flyers. Sales from the responses were even less than a half-percent. The bicycle shop owners and family members were surprised by the failure of the advertising effort.

In the final few weeks before Christmas of 2000, the Innovation Enterprises members allowed some friends who had small street vendor operations in the eastern section of the Capitol City metropolitan area to carry some scooters on consignment to see if people stopping at the small corner operations would be interested in scooters. Again, the response was extremely minimal.

Additionally, other business associates of one of the family members had Christmas tree lots in the Capitol City area and began stocking the SMOOTHX scooters in some of those locations. Again, the consumer response was negligible. Nothing seemed to work. Consumer responses seemed to be either that scooters were unsafe, or that the SMOOTHX scooters were too expensive compared to the other non-KNIFE brands in the market. The KNIFE brand sales in the Capitol City area also seemed to be suffering, and several price discounts had been offered in some of the retail outlets carrying the KNIFE scooters.

Friends of the family members suggested placing SMOOTHX scooters on the eBay website for auction. Unfortunately, by the end of November 2000, there were literally hundreds of listings on the website for the cheap scooters and for KNIFE scooters. Only two scooters were sold via the Internet.

\section{Damage Control}

By the final two weeks before Christmas of 2000, JP realized that damage control was going to be necessary. There was no hope of selling very many of the scooters; the family began shifting the company's resources in ways to minimize the cost of the capital invested in the scooter inventory and began selling the scooters directly through business associates, friends and family members. While those sales were few in number and involved keeping sales tax records and making sales tax payments to local municipalities and the state that the family members had hoped to avoid, they were generating some small cash flow. By this time, it was decided that selling the scooters at cost would be about the best that could be hoped for in the current circumstances. 
Based on the original order cost, the advertising cost, the already accumulated cost of capital, the time that had been invested in the project by family members, the $\$ 5,000$ cost of insurance (required for retail sales) and the anticipated storage costs over time, JP determined that the actual cost on the scooters had risen to approximately $\$ 60$ per scooter. Therefore, any new wholesale sales would be priced at $\$ 60$ per scooter and any direct retail sales would be priced at $\$ 65$ to cover cost and sales tax. Even with these prices, sales did not increase.

\section{Luck and Strategy - Strange Bedfellows}

A strange stroke of luck then occurred. One of the most popular morning radio drivetime programs in Capitol City was based on the conversations and personalities of the two hosts. Trent and Jan, the hosts, would typically comment about their lives and the various news stories and anecdotes coming from the news services. Two weeks before Christmas, Jan mentioned that she was having trouble finding good scooters for some children who wanted them for Christmas presents. One of the Innovation Enterprises company members heard the radio show that morning, called the station, and was unexpectedly put on the air with Trent and Jan. They were given the opportunity to explain that Innovation Enterprises had acquired 4,000 scooters made by the same company that made the KNIFE scooters and would sell them at cost plus tax. The radio hosts asked for a telephone number for Innovation Enterprises and the family member gave out two numbers. Both numbers immediately became swamped with phone calls. Other family members were called and came to help take phone calls and handle what became a stream of customers to the residence of one of the family.

Literally in a matter of minutes, what had been an almost total lack of sales became a flood of sales. Over the next several days, the radio show continued to give out the Innovation Enterprises numbers to people who called the radio station and by the last few days before Christmas, almost 400 scooters had been sold directly to the public. The bicycle shops had only sold about 100 scooters by Christmas.

\section{Fine Tuning the Strategy}

At the arrival of New Year's Day 2001, JP decided to try to help a Capitol City area nonprofit organization that specialized in dealing with troubled families and youth. While the family members knew that they could not recover the full cost of the scooters, they decided to attempt at least to generate some more cash flow by promoting the fact that Innovation Enterprises would donate a significant portion of the cash flow (about 15\%) from scooters in the month of January to the non-profit organization. An AM talk radio station was contacted and an advertising arrangement was obtained in which for discounted advertising rates, Innovation Enterprises and the non-profit organization would run two weeks of advertisements during the station's most popular broadcast hours and do a live broadcast from one of the Capitol City's suburbs during a January holiday festival. The radio station's management team wanted to help the non-profit organization as much as possible, so Innovation Enterprises was only responsible for 
$\$ 1,000$ of airtime charges. Once again, this attempt to attract customers was not successful and not a single unit was sold.

"Remember," JP told himself, "The world is dynamic; things change." But a strategy that changes every fifteen minutes is hard to manage!

\section{A "Creeping" Strategy}

The end of January 2001 found the family members of Innovation Enterprises contemplating what to do next. As they considered the amount of money still invested in the scooter inventory (approximately $\$ 160,000$ by this time) and what they might be able to recoup from drastically discounting the price of the scooters, they found themselves tending to believe that holding the scooters for a while longer wasn't such a bad idea. The alternative investment ideas for any capital were still fairly limited at the time, and the cost of the capital had been reduced to $7 \%$ by some internal financing. The storage costs of $\$ 3$ per day were ongoing, but given how badly the scooter market had collapsed, the company estimated that if it were to price the scooters in order to clear the inventory, the proceeds might be as low as $\$ 70,000$ leaving a loss of about $\$ 90,000$. The family members voted to simply hold the inventory and look for opportunities later in 2001.

The final challenge to the SMOOTHX brand of scooters and the family members' hopes of placing the scooters in retail outlets came when the manufacturer of the SMOOTHX and KNIFE scooters allowed its ownership of a website domain address to lapse. The web address was printed on every SMOOTHX carton, and before Innovation Enterprises discovered that the website ownership had lapsed, an unknown entity based in the United States obtained the domain name. Unfortunately, the new domain operator decided to open a site for the sale of pornography using the domain name. The family members would have to somehow cover the web address on the cartons with some other labeling or purchase the domain name. Offers to buy the domain name were made, but none were accepted.

\section{A Quantum Change in Strategy Is Needed for the Future}

Unfortunately, in March 2001, a family member of the company unexpectedly passed away, and that put the business activities on hold in most areas as the family dealt with family, estate and tax issues. The scooters became a "forgotten" issue.

JP had found himself in the summer of 2001 looking into the container at the trucking company's facility and wondering if the world could have been any more dynamic than it had been in the last twelve months. Roughly 3400 scooters remained. The cost of the $\$ 160,000$ in capital remained at $7 \%$, but there had not been any changes in the prices for scooters in the last six months. The market still had too many cheap imitations, and even the KNIFE scooters were hardly moving in the stores. 
"Should we dump the scooters at whatever price we could get? The stock market is still in the doldrums, so investing any amount obtained for the scooters in the market is not very attractive," JP had mused to himself. No other new business ideas had materialized among the family members and the ongoing endeavors wouldn't earn larger returns with more investments. The scooters had become a money sink, draining about $\$ 12,000$ in the last year's costs from other Innovation Enterprises activities in addition to tying up about $\$ 160,000$ in capital. Fortunately, almost all of that monetary loss was actually kept inside the boundaries of the members' other endeavors and the losses helped offset gains elsewhere for tax purposes, but the inventory simply sat there with all that capital invested in it.

"What should we do as a family business to prevent this sort of thing happening again? Why didn't we see this coming, given all our business experience and education? Why didn't the financial projections give off some red lights to warn us about this?"

In those summer months of 2001, JP had been tired. He had been tired of thinking. He had been tired of looking at scooters and his family had been tired of all the trouble that had come from the scooters. He'd closed the container's doors and driven away. He'd think about scooters another day. He was too tired.

Now, in 2004 looking at scooters on the internet with his nephew, JP felt tired all over again. Where were the mistakes? What could have been done differently once the scooter market had collapsed? Was there anything that could have been done or had the effort been caught in events that made anything attempted futile? The same questions came back every time he thought about scooters. JP was still tired. 


\section{REFERENCES}

Anonymous. 2004. The Bratz Stylin' Scooter by MGA Entertainment, $\$ 24.95$.

Retrieved from www.walmart.com

Anonymous. 2004. The Dellemann Mountainscootboard, \$424. Retrieved from www.scootboard.net

Anonymous. 2004. The Fisher-Price All-Terrain Switchboard, \$37.88. Retrieved from http://www.walmart.com

Anonymous. 2004. The Razor Rollerboard Scooter, $\$ 40$. Retrieved from http://extremetoys.com

McGinn, Daniel. 2000. Scooters: The making of a fad. Newsweek, July 24: 38-39.

Orecklin, Michele. 2000. Scooting around in style: There's nothing pedestrian about these hot wheels. Time, June 5: 55.

Oster, S.M. 1990. Modern Competitive Analysis. New York: Oxford University Press, 4.

Thompson, A.A., \& Strickland, A.J. 1999. Strategic Management. Burr Ridge, Illinois: Richard D. Irwin. 